Western University Scholarship@Western

Geography Publications

Geography Department

3-1991

How Do Gravel-Bed Rivers Braid?

Peter Ashmore

University of Western Ontario

Follow this and additional works at: https://ir.lib.uwo.ca/geographypub

Part of the Geography Commons

Citation of this paper:

Ashmore, Peter, "How Do Gravel-Bed Rivers Braid?" (1991). Geography Publications. 292.

https://ir.lib.uwo.ca/geographypub/292 


\title{
How do gravel-bed rivers braid?
}

\author{
Peter E. Ashmore \\ Department of Geography, The University of Western Ontario, London, Ont., Canada N6A 5C2
}

Received August 10, 1990

Revision accepted November 22, 1990

\begin{abstract}
Sedimentary processes and bed forms leading to the onset of braiding were observed in small-scale hydraulic models of gravel-bed streams. The laboratory streams had a variety of combinations of (constant) discharge and slope but identical bed-material particle-size distributions. From initially straight channels, braiding occurred by four different processes: deposition and accumulation of a central bar, chute cutoff of point bars, conversion of single transverse unit bars to mid-channel braid bars, and dissection of multiple bars. In these experiments the chute cutoff mechanism was the most common, but the predominant braiding mechanism depends upon sediment mobility (excess bed shear stress) and the bed-form regime. At very low excess bed shear stress the central bar process dominates, but at higher excess bed shear stress slip-face unit bars are more common, bed scour at confluences is more pronounced, and propogation of alternate convergence (scour) and divergence (deposition) is more likely; thus chute cutoffs and bar conversion dominate. The multiple bar mechanism is restricted to channels with very high width/depth ratio. All of these processes, along with avulsion, are significant for maintenance of an established braided channel.

The direct physical sedimentary cause of primary braiding is essentially the same in all these processes: local aggradation (often by stalling of bed-load sheets) and loss of competence in a lateral flow expansion. The chute cutoff process occurs in a morphologically distinctive setting and may be aided by other factors, but it is usually triggered by the local thalweg shoaling that is the fundamental physical mechanism causing the onset of braiding by the other processes. Local short-term pulses in bed-load supply are often the trigger for the initiation and maintenance of braiding, regardless of the exact braiding process.
\end{abstract}

Les processus sédimentaires et les formes de litage qui sont associés au développement d'un réseau anastomosé ont été observés par modélisation hydraulique de filets d'eau sur lit de gravier, à une échelle réduite. Les filets d'eau utilisés en laboratoire combinaient diverses conditions de débit (constant) et de pente, cependant les distributions granulométriques du matériel du lit de sédiment étaient toujours les mêmes. Quatre processus ont modifié les chenaux rectilignes initiaux et ont contribué à créer un réseau anastomosé : dépôt et accumulation d'une barre centrale, recoupement transversal des lobes de méandre, transformation de barres transversales individuelles en barres anastomosées à chenaux multiples, et dissection des barres multiples. Le processus le plus souvent observé dans cette expérimentation fut le recoupement transversal des lobes méandriques, toutefois le mécanisme dominant dans la formation du réseau anastomosé dépend de la mobilité du sédiment (force supérieure au seuil de cisaillement du lit) et du régime des formes de litage. Le processus de formation des barres centrales prédomine en présence d'une très faible force excédante au seuil de cisaillement du lit, tandis qu'une force fortement supérieure au seuil de cisaillement favorise l'apparition de barres isolées face au courant, l'affouillement aux confluences devient plus intense, la propagation de zones de convergence (affouillement) et de divergence (sédimentation) est plus fréquente, et ainsi prédominent le recoupement transversal des lobes et le façonnage des barres. Le mécanisme de formation des barres multiples est limité aux chenaux ayant un rapport largeur/profondeur élevé. Tous ces processus, incluant l'avulsion, sont importants pour préserver le chenal anastomosé établi.

La cause physique sédimentaire directe du développement du réseau anastomosé primaire est essentiellement la même dans tous ces processus : accumulation locale (souvent par immobilisation de la charge de fond des lits) et perte d'énergie de l'écoulement d'étendue latéral. Le processus de recoupement des lobes méandriques apparaît dans un contexte morphologiquement distinct et il peut être intensifié par d'autres facteurs, mais il débute généralement grâce à un haut-fond de vallée qui constitue la cause physique fondammentale de la formation du réseau anastomosé due aux autres processus. Des venues subites de charge de sédiment plus volumineuses servent souvent à amorcer et à maintenir le développement du réseau anastomosé, indépendamment de son processus exact de formation.

Can. J. Earth Sci. 28, 326-341 (1991)

[Traduit par la rédaction]

\section{Introduction}

Explanations of the causes of braiding in alluvial streams fall into two general categories. The first is a functional explanation relating the occurrence of braiding to a particular combination of externally imposed environmental factors such as stream discharge, channel or valley gradient, sediment particle size, and bank resistance, and exemplified by Leopold and Wolman's (1957) recognition of a threshold slope for braiding. Alternatively, explanations have been sought through stability analysis of channel-scale bed forms in two-phase flow (Engelund and Skovgaard 1973; Parker 1976; Fredsoe 1978). Neither of these approaches explicitly considers the physical sedimentary processes accompanying the onset of braiding, which need careful description and analysis before any complete explanation of the phenomenon is possible (Carson 1984a; Fujita 1989). A rational analysis of this kind would help us understand the functional relationships, and would complement stability analyses by describing the nature of the sedimentary features and processes resulting from instability of the two-phase flow.

In this paper I approach the explanation of braiding by $(i)$ describing the sedimentary processes accompanying its onset; (ii) examining the hydraulic conditions under which each sedimentary process and the associated bed forms occur; and (iii) proposing underlying physical mechanisms. In other words, I attempt to answer the question of how rivers braid in terms of the sedimentation phenomena involved. This is done by using observations of sedimentary processes leading to braiding in small-scale hydraulic models of gravel-bed streams, which permits elaboration of existing field descriptions of these processes. This approach provides a unified set of observations of the sedimentary processes accompanying the onset of braiding under controlled conditions, in which the sedimentary 
features are clearly visible beneath the water. These new data are used to define the sedimentary processes by which rivers braid and to instill some order into existing descriptions, which come from a wide variety of hydraulic and sedimentologic conditions and which often use quite different terminology.

Throughout the paper "braiding" is taken to be the result of active erosion and deposition within a channel, rather than simply the result of stage variations causing the emergence and dissection of bar surfaces. Furthermore, "braiding" is defined as a distinct bifurcation of the flow and (or) bed-load flux around inactive (sensibly zero bed load) portions of the channel bed, and need not neccessarily involve exposure of an inactive bar above the water surface (the latter is the more classical view of braiding).

The central bar braiding mechanism (which epitomizes the above definition) described by Leopold and Wolman (1957) in a small laboratory stream is the braiding process most frequently cited in standard fluvial geomorphology texts, and often the only one (e.g., Richards 1982; Knighton 1984; Morisawa 1985). Its essential feature is the development of a submerged mid-channel bar initiated by local decline in competence and deposition of the coarsest fraction of the bed load. Several other processes have been observed in both laboratory models and prototype streams.

The most commonly reported alternative braiding process in gravel-bed streams and in laboratory streams formed in sand (some of which are effectively scaled-down gravel-bed streams) is the chute cutoff of point bars in low-sinuosity channels (Friedkin 1945; Kinoshita 1957; Krigström 1962; Hickin 1969; Ikeda 1973; Hong and Davies 1979; Ashmore 1982; Ferguson and Werrity 1983; Bridge 1985). Lewin (1976) has described the early stages of this process in a straightened gravel-bed stream, which later became braided in places (J. Lewin, personal communication, 1988), and Carson (1986) has reported frequent chute cutoff of point bars in high energy, meandering gravel-bed streams. Both chute cutoff and central bar mechanisms were illustrated in field studies on Icelandic outwash plains by Krigström (1962, Figs. 2-4, 6, 9).

In addition, braiding has been seen to be the result of dissection of transverse unit bars (Smith 1974) developed downstream of confined channel sections or flow confluences (Krigström 1962; Hein and Walker 1977; Ashmore 1982; Rundle 1985a, 1985 b; Davoren and Mosley 1986). In fact, Rundle $(1985 a, 1985 b)$, after dismissing the central bar mechanism of Leopold and Wolman as a braiding process, proposed "dissection of tongue structures" during falling stage as the dominant braiding mechanism in gravel-bed braided streams. The dissection of "chute and lobe" forms leading to braiding in very shallow, steep, gravelly outwash streams (Southard et al. 1984) and of "diffuse gravel sheets" in others (Hein and Walker 1977) may be essentially the same process as transverse bar dissection but restricted to poorly sorted gravel and very small relative depths.

Finally, Fujita and Muramoto (1988) and Fujita (1989) reported a slightly different braiding mechanism prevalent in very wide, steep flumes with shallow flow. In these experiments an initial, scale-like arrangement of numerous multiple bars is gradually converted to fewer, larger bars which concentrate the flow into scour hollows, leading to dissection and emergence of portions of the bed (e.g., Fujita 1989, runs C3 and C8), and hence a braided channel.

Once braiding is established, it may be perpetuated by the repetition of one or more of the braiding mechanisms identified above or by "secondary anastamosis" (Church 1972) - the reoccupation of previously abandoned channels (Krigström 1962; Ferguson and Werrity 1983; Carson 1984b, 1984c).

\section{Experimental equipment and procedure}

Parker (1979), Ashmore (1982), Ashmore and Parker (1983), Southard et al. (1984), and Davies and Lee (1988) have shown that the principles of hydraulic modelling can be applied to gravel-bed, braided streams to produce laboratory channels that are Froude models of prototype streams. Yalin (1971, pp. 111115) gave a lucid account of the principles involved and their application to mobile bed models with rough, turbulent flow. Without changing the fluid viscosity it is impossible to satisfy both Froude and Reynolds similarity criteria in the same model. Froude models overcome this difficulty by relaxing the Reynơlds similarity criterion for flows that are hydraulically rough and turbulent. In this case it is important that the model-scale ratio be sufficiently small to maintain the particle Reynolds number $\left(\left(u^{*} D_{90} \rho\right) / \mu\right.$, where $u^{*}$ is shear velocity, $\rho$ is fluid density, and $\mu$ is molecular viscosity) greater than approximately 70 for a hydraulically rough boundary, and the flow Reynolds number greater than 2000 to maintain fully turbulent flow. Provided that this relaxed Reynolds criterion is satisfied, the relevant physics of the model (for example, flow resistance and sediment transport) are the same as for the prototype.

The streams developed using these modelling criteria, and discussed in this paper, reproduce the features and processes of gravel-bed braided streams in general, rather than the exact details of a specific river or part of a river. They are "generic models" of braided river forms and processes (M. A. Church, personal communication, 1989).

The experiments were carried out in a laboratory flume $10 \mathrm{~m}$ long by $2 \mathrm{~m}$ wide (Fig. 1a). Water was supplied to the flume from the laboratory sump and entered the flume by discharging vertically downwards from a pipe into a fibre pad (to absorb energy) placed in a wooden head section (Fig. 1b). The sediment was recirculated to the head of the flume as a sediment-water mixture pumped through a separate return pipe and introduced to the flow by way of four pipes discharging vertically down into the flume entrance immediately downstream of the water supply. The bed material consisted of poorly sorted coarse sand with $D_{50}$ of $1.16 \mathrm{~mm}, D_{95}$ of $4 \mathrm{~mm}$, and $D_{5}$ of $0.35 \mathrm{~mm}$. This is the gradation that is produced by scaling down each size fraction of a typical prototype particle, size distribution by the geometric- (length-) scale ratio of the model (Fig. 2).

The flume gradient was chosen sufficiently steep to produce braiding at the imposed discharge. From Fig. 2 the overall geometric-scale ratio is $1: 16$, giving a time scale ratio of $1: 4$. Froude number, relative depth $\left(h / D_{50}\right.$, where $h$ is the average flow depth), and nondimensional bed shear stress $\left(\tau_{0} /\left(\gamma_{\mathrm{s}} D_{50}\right)\right.$, where $\tau_{0}$ is bed shear stress and $\gamma_{\mathrm{s}}$ is the submerged specific weight of the sediment) in the laboratory channels are in the range typically found in prototype braided streams (Ashmore 1988). Particle Reynolds numbers ranged from 90 to 130 in the channels at the beginning of each experimental run (Table 1) but were lower in some of the smaller channels within the braided streams. Similarly, the flow Reynolds number ranged from 1900 to 6900 in the initial channels (Table 1) but averaged 1900 in a sample of anabranches within the braided channels. Thus, 


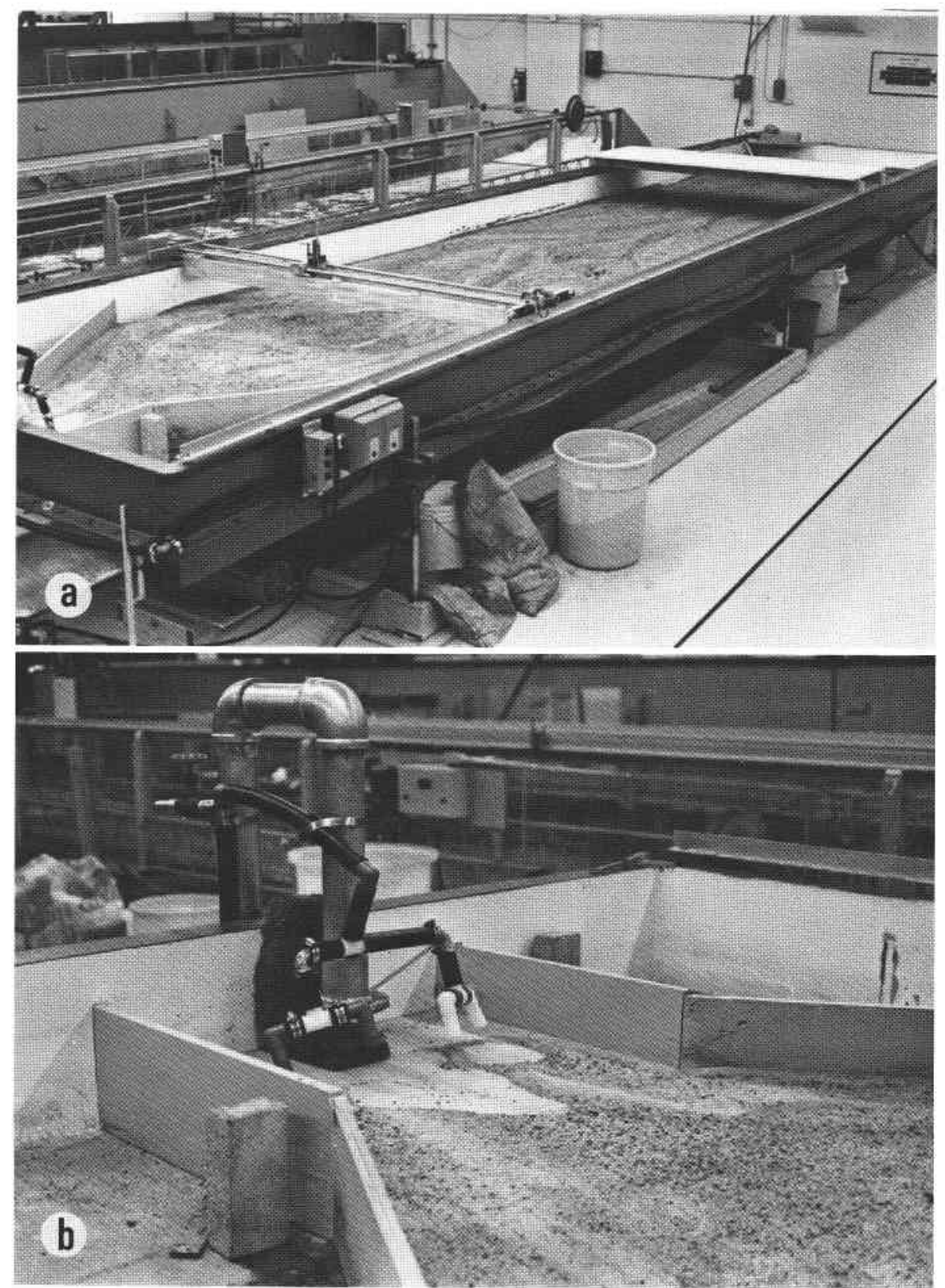

FIG, 1. (a) Laboratory flume used in the braiding experiments. (b) Detail of the flume entrance. Water entered the flume through the largediameter silver pipe and sediment was recirculated via the small-diameter black pipe and nozzles.

flow in some of the channels was bordering on transitional rather than fully turbulent.

The experiments were designed to examine the braiding mechanisms under a range of flow conditions and one bedmaterial particle-size distribution. Ten runs were carried out using different combinations of discharge and flume gradient (Table 1) but each beginning from a straight channel with trapezoidal cross section and width/depth ratio of approximately 30. An additional pair of runs, referred to as $A$ and $B$, were used to investigate the possible influence of width/depth ratio or relative depth on the initiation mechanism.

\section{Braiding mechanisms}

The bed morphology and braiding process were found to vary with the initial flow conditions, and four different braiding mechanisms are identified here. The following descriptions of each braiding mechanism are compiled from notes, hourly vertical still photographs of the flume, and time-lapse films of each run.

\section{Chute cutoff}

Initiation of braiding in most of the runs (except runs 3,7 , and B) occurred by the development of chute channels across alternating point bars developed in the initially straight channels. This chute cutoff process also occurred frequently in the established braided streams, but usually in association with single point bars rather than an alternating sequence along the channel.

Figure 3 shows an example of alternating point bar cutoff from run 10 . Immediately after the run began, the bed became covered with bed-load sheets. Antidunes were common at this stage. The sheets were lobate in plan and showed some internal 
TABLE 1. Flow conditions for the experimental runs

\begin{tabular}{|c|c|c|c|c|c|c|c|c|c|}
\hline Run & $\begin{array}{l}\text { Discharge } \\
\left(\mathrm{m}^{3} \cdot \mathrm{s}^{-1}\right)\end{array}$ & $\begin{array}{l}\text { Flume } \\
\text { slope }\end{array}$ & $\begin{array}{l}\text { Width } \\
\text { (m) }\end{array}$ & $\begin{array}{l}\text { Depth } \\
\text { (m) }\end{array}$ & $\begin{array}{c}\text { Froude } \\
\text { no. }\end{array}$ & $\begin{array}{l}\text { Nondimensional } \\
\text { bed shear stress }\end{array}$ & $\begin{array}{l}\text { Particle }\left(D_{90}\right) \\
\text { Reynolds number }\end{array}$ & $\begin{array}{l}\text { Reynolds } \\
\text { number }\end{array}$ & $\begin{array}{l}\text { Stream power } \\
\text { per unit length } \\
\left(\mathrm{W} \cdot \mathrm{m}^{-1}\right)\end{array}$ \\
\hline 1 & 0.00300 & 0.015 & 0.50 & 0.015 & 1.04 & 0.114 & 131 & 4580 & 0.441 \\
\hline 2 & 0.00300 & 0.015 & 0.50 & 0.015 & 1.04 & 0.114 & 131 & 4580 & 0.441 \\
\hline 3 & 0.00150 & 0.010 & 0.40 & 0.012 & 0.91 & 0.061 & 96 & 2862 & 0.147 \\
\hline 4 & 0.00150 & 0.015 & 0.35 & 0.011 & 1.19 & 0.083 & 113 & 3272 & 0.221 \\
\hline 6 & 0.00150 & 0.015 & 0.35 & 0.011 & 1.19 & 0.083 & 113 & 3272 & 0.221 \\
\hline 7 & 0.00150 & 0.010 & 0.40 & 0.012 & 0.91 & 0.061 & 96 & 2862 & 0.147 \\
\hline 8 & 0.00450 & 0.010 & 0.50 & 0.018 & 1.19 & 0.091 & 118 & 6870 & 0.441 \\
\hline 9 & 0.00450 & 0.015 & 0.50 & 0.017 & 1.30 & 0.129 & 140 & 6870 & 0.662 \\
\hline 10 & 0.00225 & 0.015 & 0.40 & 0.013 & 1.21 & 0.098 & 122 & 4294 & 0.331 \\
\hline 11 & 0.00120 & 0.015 & 0.30 & 0.010 & 1.28 & 0.076 & 107 & 3053 & 0.177 \\
\hline A & 0.00300 & 0.013 & 0.54 & 0.013 & 1.20 & 0.088 & 114 & 4241 & 0.383 \\
\hline B & 0.00300 & 0.013 & 1.21 & 0.008 & 1.11 & 0.054 & 89 & 1893 & 0.383 \\
\hline
\end{tabular}

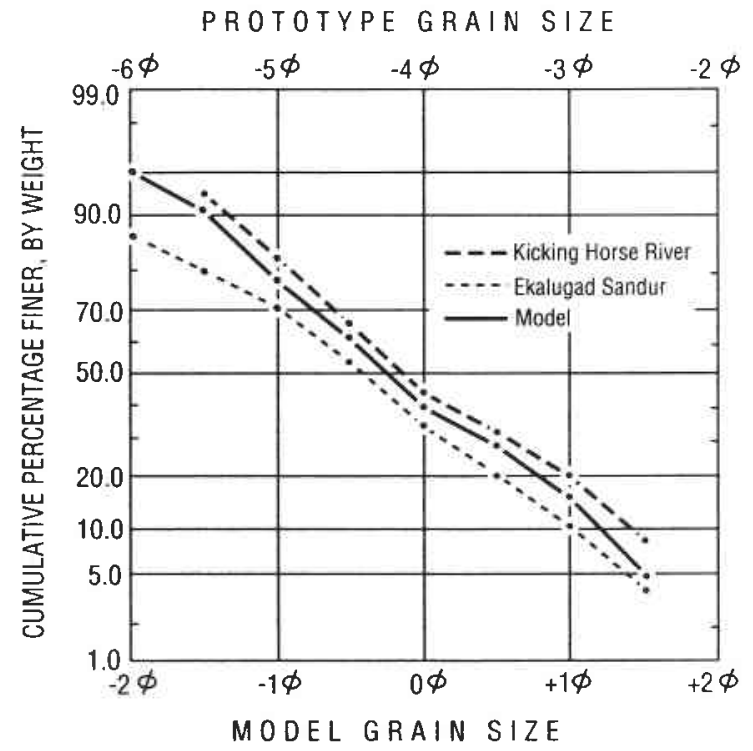

FIG. 2. Bed-material particle-size distribution for model and prototype streams. Prototype data from N. D. Smith (personal communication, 1981) and Church (1970).

sorting of sediment, with a tendency for coarse material to accumulate at the downstream margin and finer material to be concentrated near the centre. Their morphology and sedimentsorting characteristics appear to be similar to those of bed-load sheets reported by Whiting et al. (1988), and are perhaps equivalent to those of the "diffuse gravel sheets" identified by Hein and Walker (1977). The area and height of the sheets varied and smaller, thinner sheets could often be seen migrating across the surface of slower moving, thicker ones.

From this stage the channel pattern developed very rapidly, reflecting the high-bedload transport rates. Within $20 \mathrm{~min}$ of the beginning of the run the pattern resolved into a more regular set of large migratory lobate bars and scour pools on alternating sides of the channel (Fig. 3a). The spacing of these bars correlates with the width of the initial channel in the same way as riffle spacing and meander wavelength. Bar-bar spacing ranged from 6.0 to 8.3 times the width of the initial channel in the runs in which these features developed. About 15 min later, the flow in the sinuous thalweg began to erode the banks on the outside of the bend opposite each bar (Fig. $3 b$ ). Simultaneously the alternating bars were transformed into more complex point bars (Figs. $3 b, 3 c$ ) by lateral accretion of portions of migratory sheets that continued to move along the channel. The structure and sedimentary features of these point bars are similar to existing descriptions of point bars in low-sinuosity gravel-bed streams (e.g., Bluck 1976; Lewin 1976; Carson 1986) and to the features of "pseudomeanders" (Wolman and Brush 1961) and "point dunes" in laboratory streams (Hickin 1969).

Examination of the time-lapse films revealed that the onset of the cutoff process often coincided with the arrival of a pulse of bed-load from upstream in the form of a bed-load sheet or migratory transverse unit bar. The rapid point bar accretion, and concave bank erosion (and downstream translation of the cut bank) immediately upstream of the chute, accompanying the passage of these bed-forms caused more flow to be directed over the point bar, presumably assisted by local bed aggradation. J. Lewin (personal communication, 1988) similarly observed that a "slug" of sediment was responsible for the activation of a chute channel on the Ystwyth River, leading to braiding of a short reach of the river. The importance to the occurrence of braiding of this short-term pulsing in bed-load transport rates has not previously been emphasized. Its relevance appears to lie in the triggering of the cutoff in what is already an unstable channel configuration created by the stage of development of the bend and point bar.

The steep gradient near the head of the slough channels resulted in their headward erosion, capture of progressively larger volumes of water, and rapid enlargement. This can be seen most clearly at the bend just downstream of the midpoint of the flume (Fig. $3 c, \mathrm{~A}$ ). Within a few minutes the cutoff channel over this point bar was fully established (Fig. 3d, B) and enlarged to a size comparable with that of the original, main channel on the opposite side of the point bar. The original point bar, in a modified form, survived as a medial bar to which further accretion occurred as the braided pattern developed (Fig. $3 d, \mathrm{C}$ ). At the downstream end of the cutoff a large transverse bar (Fig. 3d, D), supplied by scour of the channel and increasing diversion of bed load down the chute, prograded out into the confluence downstream of the medial bar. This gradually forced the flow towards the right bank and resulted in removal of the adjacent point bar (Fig. 3e).

Apart from the several laboratory studies reporting similar braiding processes (see Bridge 1985 for a review), the published descriptions from prototype streams that bear the closest 


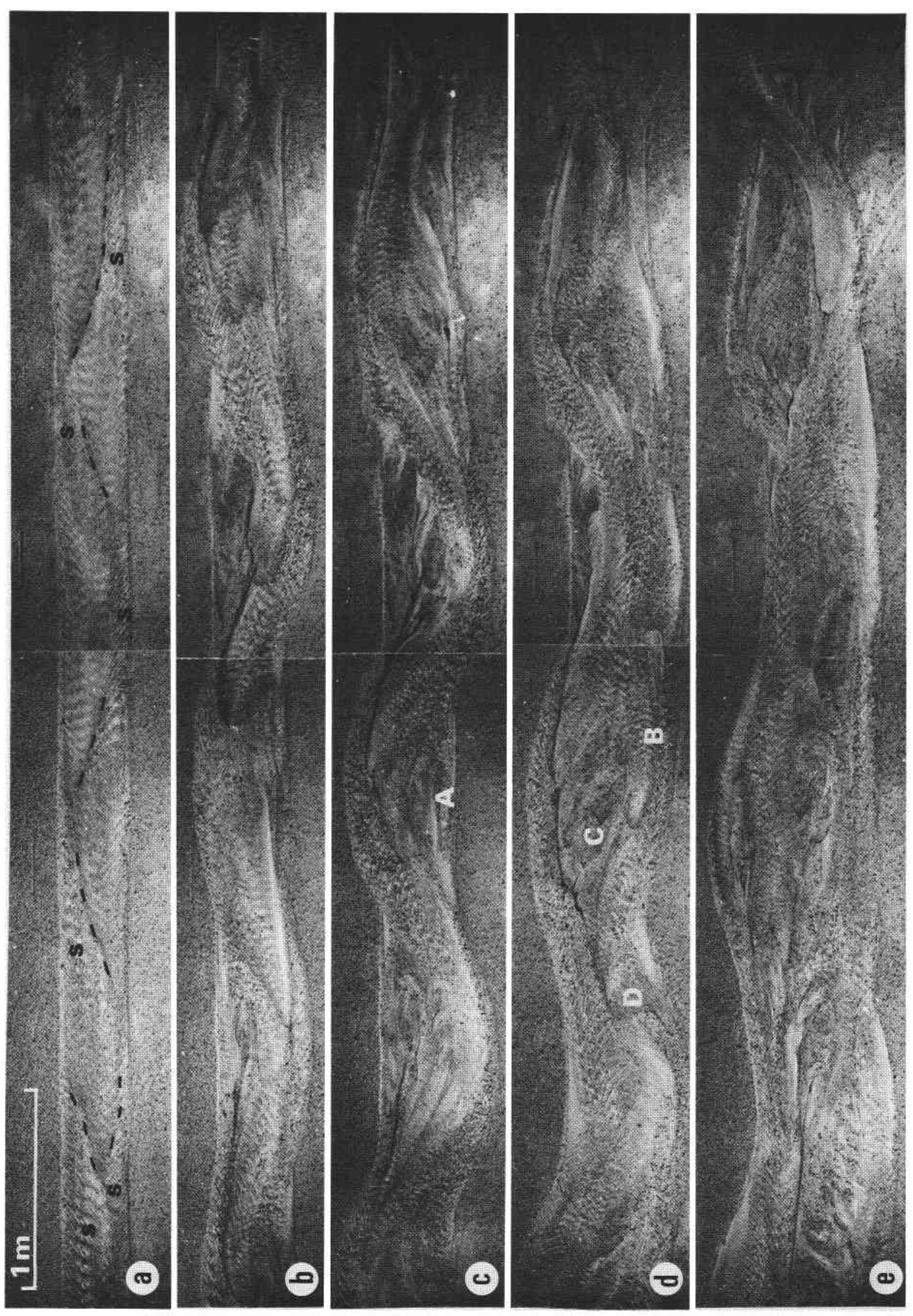

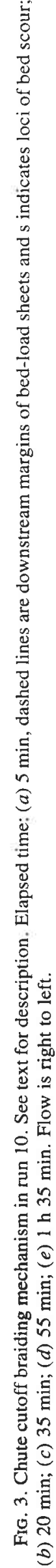



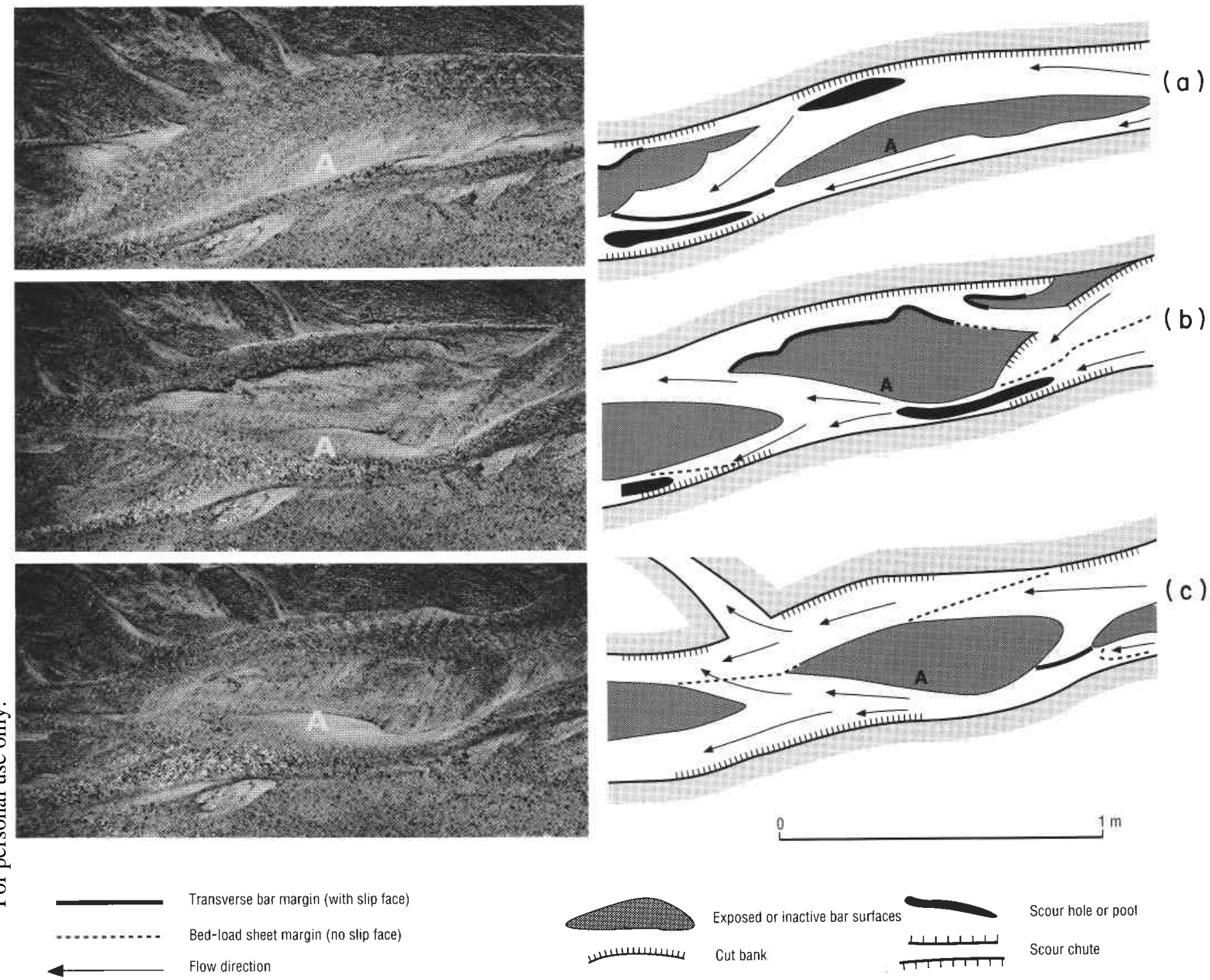

FIG. 4. Chute cutoff in an established braided channel (run 11). (a) Point bar A begins to develop. (b) After a period of growth and increasing sinuosity point bar $\mathrm{A}$ is cut off, leaving portions of the original channel abandoned and developing a new point bar on the opposite bank. (c) Point bar at A is converted to a medial bar by a second chute cutoff. The elapsed time between successive photographs is $1 \mathrm{~h}$. Flow is right to left.

resemblance to the events described from Fig. 3 are the examples of chute cutoff and slough cutoff of bars in gravel-bed meanders in New Zealand (Carson 1986), and the development of the solitary "river junction bar" and "river curve spur" of Krigström (1962) (see also, Church and Jones 1982, Fig. 11.1).

The chute cutoff process was not restricted to the initial braiding at the beginning of the runs, and therefore plays an important role in maintenance of the braided planform. Renewed braiding was often caused by cutoff of one or more low-sinuosity bends in channels newly formed or reoccupied by avulsion or experiencing increased sedimentary activity resulting from input of a bed-load pulse from upstream. Figure 4 shows three stages (Figs. $4 a-4 c$ ), $1 \mathrm{~h}$ apart, in the development of a braid bar by chute cutoff in an established braided channel (run 11). The initial point bar (Fig. 4a, A) underwent chute cutoff through the slough channel on the bankward side of the bar. Subsequently (Fig. 4b), the original main channel was completely abandoned in favour of the former slough channel. This new point bar (Fig. $4 b, \mathrm{~A}$ ), with its core inherited from the initial point bar, was converted to a braid bar (Fig. 4c, A) by reoccupation of the original main channel via another chute cutoff.

\section{Central bar initiation}

In two runs ( 3 and 7 ) braiding was very slow to develop and alternating bars (point dunes) were poorly developed. Runs 3 and 7 had the lowest stream power per unit length of channel of all the runs (Table 1) and would be expected to be the least braided. Throughout the duration of these runs the braiding index (defined as the mean number of active channels per channel cross section, taken from a stratified-random sample of 80 cross sections measured at regular intervals during each run) was 1.60 and 1.30 in runs 3 and 7 respectively. This compares with values of 1.4-2.4 in the remaining runs (Table 1).

Figure 5 shows an example of the initiation of braiding in run 7 , which occurred several hours after the beginning of the run. Prior to the onset of braiding the only change in channel morphology since the beginning of the run was some slight bank 
erosion producing a very low sinuosity channel (Fig. $5 a$ ). The bifurcation shown in Fig. 5 developed about $2 \mathrm{~m}$ from the flume entrance immediately downstream of the flow convergence created as a result of deposition in the flume entrance. The bifurcation sequence began with the migration of an elongate, bed-load sheet (Fig. 5a, A) downstream of the convergence, which was responsible for aggradation of the channel. This sheet appeared to be only two or three grains thick at its downstream edge and little, if any, bed-load movement was apparent in the channel downstream of the sheet margin.

A few minutes later, a second sheet, barely visible because it was little more than one grain thick, advanced across the surface of the first. This sheet, typical of those observed in all the runs, was internally sorted with an accumulation of coarse particles at the downstream margin. The downstream margin of this second sheet stalled a short distance downstream of the confluence (Fig. 5a, B) and the coarse downstream margin of this sheet formed the sedimentary nucleus of the mid-channel bar that caused the onset of braiding. This coarse sediment at the margin corresponds to Leopold and Wolman's (1957) initial accumulation of coarse particles, but its origin appears to be slightly different from the simple decrease in competence inferred by Leopold and Wolman (1957).

Gradually the central bar emerged further and was enlarged by the lateral and headward accretion of portions of bed-load sheets that passed along the channel (Figs. 5b-5d). The bedload sheets (Fig. $5 b, \mathrm{C}$ ) and the resulting accretion features (Fig. 5d, D) were most apparent on the left-hand side of the bar. This accretion process was also accompanied by progressive downstream fining of the bar sediment, due to selective sorting of bed load around the central bar-coarser sediment was deposited on the upstream bar margin while finer sediment was transported through the bend to the downstream margin of the bar (Fig. $5 d$ ).

When this description and the accompanying illustrations are compared with those of Leopold and Wolman (1957) there is a striking similarity. Leopold and Wolman (1957) described the flow initially being deflected around a submerged bar and causing slight erosion of the adjacent bank. At this stage the zone of most active bed-load transport lay over the top of the submerged bar, indicating that the bar may have been a bed-load sheet of the kind described above, although not interpreted as such by Leopold and Wolman (1957). Leopold and Wolman's (1957) subsequent description includes reference to the progressive deposition of fine sediment near the downstream end of the bar in the form of "foreset beds as in a delta" (Leopold and Wolman 1957, p. 47). These features are visible in Fig. $5 b$.

A further similarity with Leopold and Wolman's (1957) description is that the central bar developed only 2 or $3 \mathrm{~m}$ from the flume entrance in a channel devoid of any other braiding activity. The location of the braid bar seems to be an artifact of the arrangement of the flume entrance conditions (see comment in Schumm et al. 1987, pp. 156-157). However, the feature itself is not and equivalent morphologies are commonly seen in flow expansions in prototype streams.

\section{Transverse bar conversion}

Lobate, migratory, transverse unit bars (Smith 1974; Church and Jones 1982), often with lee slip faces, were common in all the experimental runs, although they were more numerous and better developed in those with higher discharge and slope. In some runs braiding was initiated by flow division around the downstream end of a symmetrical transverse unit bar. Figure 6 shows an example of this process in run 2.
Bar formation was initiated from a symmetrical transverse unit bar (Smith 1974) (Fig. 6a, B) formed downstream of a confluence scour (Fig. 6a, A), a situation typical of braided streams (Smith 1974; Ashmore 1982; Davoren and Mosley 1986; Ferguson 1987). The well-defined downstream margin of this bar was marked by the accumulation of coarser bed material. In places a low slip face developed, but in the centre of the downstream margin the bar had a fairly gently sloping face. Sediment was transported across the lateral margins of the bar but the central portion of the lee face stalled in the channel.

Another important feature of this process was the appearance of bed-load sheets moving downstream across the surface of the larger unit bar. Frame by frame analysis of the time-lapse film revealed that over a period of $10 \mathrm{~min}$, during which braiding was initiated, five such sheets migrated over the surface of the bar. The sketches $(1-5)$ in Fig. $6 b$ illustrate this sequence of events. The sheets appeared not to pass beyond the margin of the bar and therefore presumably contributed to vertical accretion of the bar surface or progradation of the slip face. The first four sheets maintained their lobate planform as they migrated across the bar surface, but the fifth developed an indentation near the centre, indicating that the migration rate of this portion of the sheet slowed down relative to the lateral margins. The accretion of the fifth sheet appeared to mark the beginning of flow diversion around the central part of the bar margin, although it is impossible to be certain whether this is cause or effect.

Figure $6 c$ shows the situation $10 \mathrm{~min}$ after the photograph in Fig. $6 a$ was taken. The flow had divided around the bar margin, which was marked by the accumulation of coarse material in the centre of the channel (Fig. $6 c, \mathrm{~B}$ ). The bar margin had deformed to become two asymmetrical (diagonal) bars ( $\mathrm{C}$ and $\mathrm{D}$ ) across which the flow diverged. Subsequent enlargement of the resulting medial bar occurred by lateral accretion and downstream extension on both sides, in much the same manner as point bar accretion in the chute cutoff example (Fig. 3d), and as described previously by Bluck $(1976,1979)$ and Ashmore (1982).

This process appears to have many of the features of "spool bar" development described by Krigström (1962), although in the case described here, multiple dissection of the bar front did not occur. Furthermore, the medial bar ("spool bar") was built by gradual lateral accretion rather than formation entirely by falling-stage modification of the transverse bar, as Krigström (1962) and, subsequently, Church and Jones (1982) implied. Rundle $(1985 a, 1985 b)$ has also emphasized the process of dissection of these tongue-shaped structures as the primary braiding mechanism. However, Rundle $(1985 a, 1985 b)$ is explicit about the fact that much of the dissection and braiding occurs during a fall in discharge and involves the formation of multiple chutes, rather than a single bifurcation. Similarly, falling-stage dissection of transverse unit bars causing braiding is described in studies of proglacial outwash by Smith (1974) and Hein and Walker (1977).

The foregoing description of "transverse bar conversion" indicates that there is no necessity for falling discharge in this braiding process, although water surface elevation may drop locally as the channel widens and dissection of the bar commences. Thus, braiding by this process can occur at constant discharge. From the observations reported here, dissection of the lobate bar appears to be the result of vertical accretion to the bar surface causing a reduction in flow depth on the bar top, combined with a decrease in the longitudinal gradient as the bar progrades downstream. The result is diversion of the flow over the lateral margins of the bar, aided by 


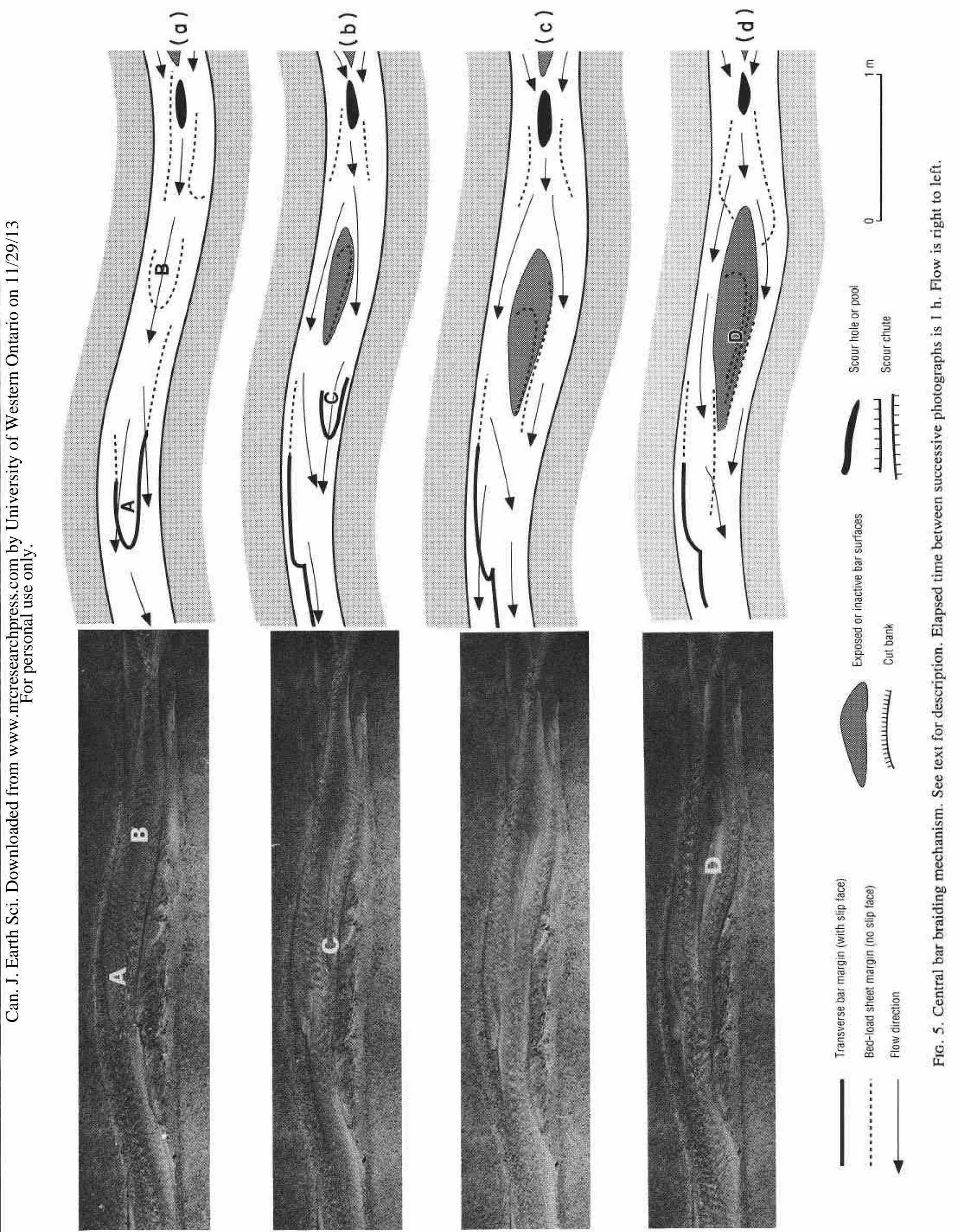


the steeper bed gradient there. While there is no necessity for a drop in discharge to accomplish this conversion, declining discharge could produce the same relative change in bar surface and water surface elevations. Such falling-stage dissection may aid the process of braiding in protoype streams (Smith 1974, 1985).

\section{Multiple bar braiding}

Figure 7 illustrates the sequence of events leading to braiding in an experiment in which the initial channel had a width/depth ratio of $140, h / D_{90}$ of 3 , discharge of $0.003 \mathrm{~m}^{3} \cdot \mathrm{s}^{-1}$ and slope of 0.013 (run B). At the same slope and discharge, but with a width/depth ratio of 40 and $h / D_{90}$ of 6 (run A), braiding was initiated by the chute cutoff mechanism described previously. With much lower relative depth and greater width, however, alternating bar development was inhibited and braiding developed by a different process.

Initially, flow was concentrated into isolated, discontinuous chutes marked by pronounced waves on the water surface and antidunes on the bed. Bed-load transport occurred along these chutes, but the sediment was often deposited as thin lobate sheets at the downstream end of these channels. This gave the bed an appearance similar to, but less regular than, the multiple-row bars described by several Japanese workers as the precursor of braiding in channels with very high width/depth ratio (Fujita 1989). Eventually some of these channels became better established and local bed scour began to occur (Fig. 7a). Sedimentary tongues or bars were deposited downstream of these erosional chutes (e.g., Fig. $7 a$, A) and flow division occurred around these tongues. This pattern of discontinuous chute channels gradually resolved into a more definite network of interconnected channels into which the flow became concentrated (Fig. $7 b$ ). A major scour channel at the centre of the flume near the entrance seemed to dominate the flow pattern (Fig. $7 b$, B) and lead ultimately to the development of a channel confluence and a large medial bar in the centre of the flume. The intervening areas of the original bed, and some of the sedimentary sheets, were then left as medial bar complexes (e.g., Fig. $7 c, \mathrm{C}$ ) in a braided channel whose morphology was essentially identical to those formed by the cutoff mechanism (Fig. 7c).

\section{Hydraulic conditions controlling braiding mechanism}

Each of the four braiding mechanisms descibed above occurs under slightly different initial conditions of channel dimensions and sediment mobility. The objectives of this portion of the paper are to clarify those conditions, and identify important distinctions or similarities in the sedimentary processes between each of the braiding mechanisms. This leads to a clarification of the reasons for the occurrence of a particular braiding process under given conditions of hydraulics and sediment transport, and identification of the fundamental mechanisms to be understood in explaining the onset and maintenance of braiding.

\section{Central bar versus chute cutoff braiding}

There is a clear contrast between the bed-forms developed at the beginning of the runs in which these braiding mechanisms occurred: transverse unit bars with slip faces (which developed an alternating pattern from which point bar growth was initiated) in the chute cutoff case, contrasted by very poorly defined sheets in the central bar case. The sedimentary processes leading to braiding directly reflect this contrast.

Bed forms in shallow gravel-bed streams, such as the diffuse sheets and lobes described here, have been observed by numerous researchers, yet the hydraulic conditions governing their occurrence and form have not been systematically investigated. However, if the geometry (especially bar heights or scour depths) of migratory gravel bars or more stable alternating bars responds to hydraulic conditions (as do subaqueous dunes (as defined by Ashley 1990) in sand), one would expect excess nondimensional bed shear stress (nondimensional bed shear stress (defined above) minus critical nondimensional bed shear stress) and relative depth to exert a major influence on their dimensions (Yalin 1977, pp. 240-254; Allen 1982, Figs. 824). The confirmation of this assumption awaits the appropriate experimental results, but as a hypothesis it appears to explain the differences in bed forms between the two cases, which directly influences the nature of the braiding processes.

Nondimensional bed shear stress in the centre of the initial channels was approximately 0.06 in runs 3 and 7 (the two runs in which central bar braiding occurred) but was between 0.09 and 0.13 in the remaining runs (Table 1). As a first approximation, a Shields criterion for critical nondimensional bed shear stress of 0.06 is reasonable and indicates that runs 3 and 7 had bed shear stress very close to critical and the remaining runs had bed shear stress well in excess of critical. Thus, the distinction between the sedimentary features associated with these two braiding mechanisms might be attributed to differences in sediment mobility and hence bed-form regime. Runs 3 and 7 have mean bed-load transport rates (for the entire run) of 0.0017 and $0.0011 \mathrm{~kg} \cdot \mathrm{s}^{-1}$, compared with an average mean bed-load transport of $0.0078 \mathrm{~kg} \cdot \mathrm{s}^{-1}$ for the remaining runs. (See Ashmore (1988) for details of the data on bed-load transport rates in these experiments.)

In both cases the first step towards braiding is the stalling of migrating sheets or bars in the channel. In the central bar case this appears to occur because of slight changes of competence near the centre of the channel. In the chute cutoff case the process begins with the emplacement of alternating bars. Thalweg deflection to alternating sides of the channel, due to an inherent instability in the flow, allows local bed scour and lowering of the water surface over the bars, so inducing their initial stalling, from which point bar accretion and finally chute cutoffs develop. Higher sediment mobility would encourage greater scour and more pronounced bed topography. Progression to a point at which chute cutoff occurs depends to some extent on bank stability. There are many examples, particularly in flumes, of alternating bars forming, but not progressing to point bar formation and cutoff because of preclusion of lateral erosion of the channel (lkeda 1984; Jaeggi 1984). Thus, the conditions under which alternate bar formation is prominent may be important to the distinction between chute cutoff and central bar braiding, but a complete description of the conditions for the development of chute cutoff must include bend widening and bank stability. The importance of alternate bar or point bar formation provides a useful link between the explanation of braiding based on the sedimentary phenomena and the explanation of braiding from stability analyses of channel-scale bed forms.

Although not specifically tested here, relative depth may also be a factor in controlling braid mechanisms and braid morphology. In very steep channels in coarse gravel, bed shear stress may be well above critical but bar development may be restricted by relative depth. In the experiments reported here the relative depths at the beginning of the runs were $2.5 \leq h / D_{90} \leq$ 4.5 , and $8.3 \leq h / D_{50} \leq 15$. In the established braided channels (see Ashmore 1988, Table II) the relative depths were $2.0 \leq$ $h / D_{90} \leq 2.8$, and $6.5 \leq h / D_{50} 9.0$. Thus, an approximate lower limit for bar development is $h / D_{90}<2.0$ and $h / D_{50}<6.0$. 


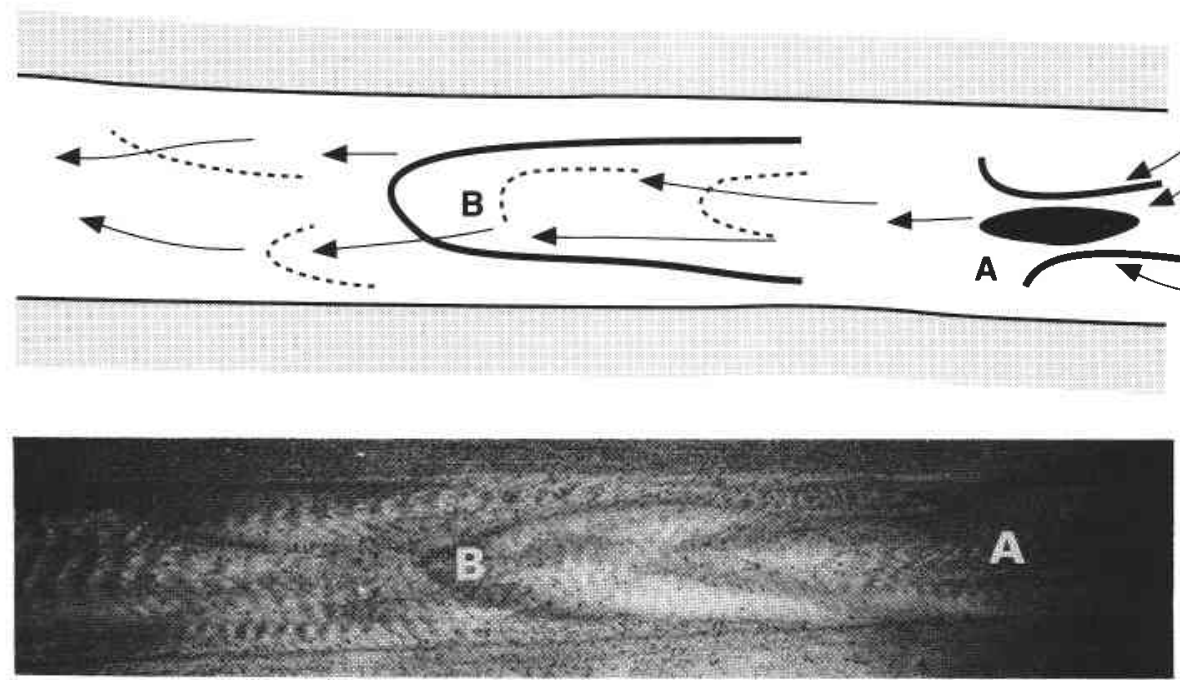

(a)
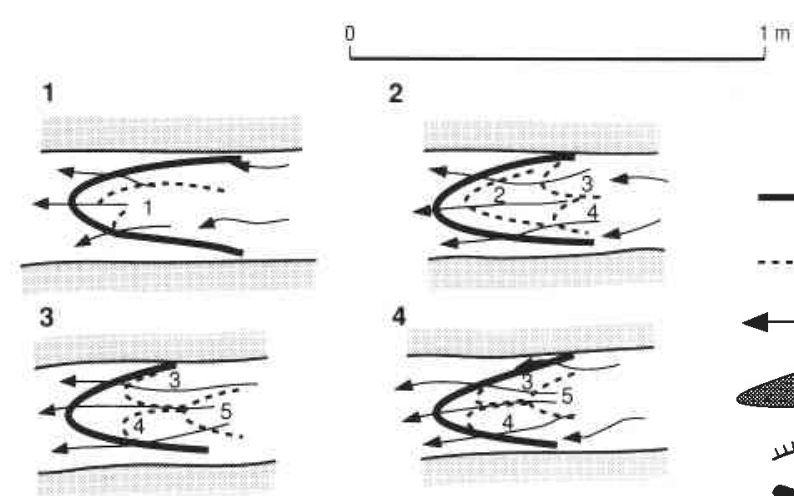

5

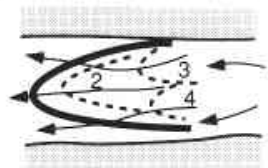

4
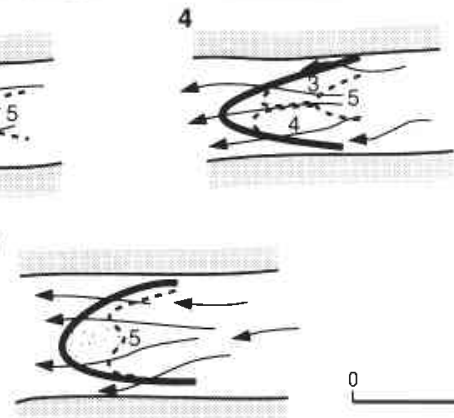

$1 \mathrm{~m}$

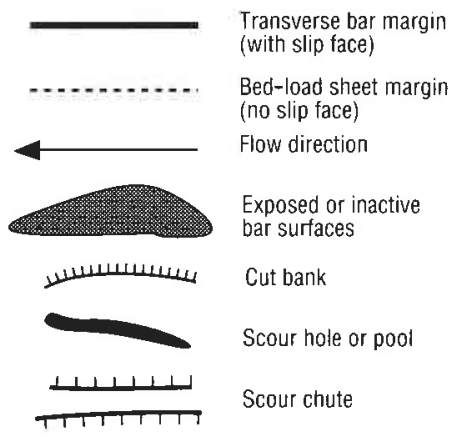

(b)
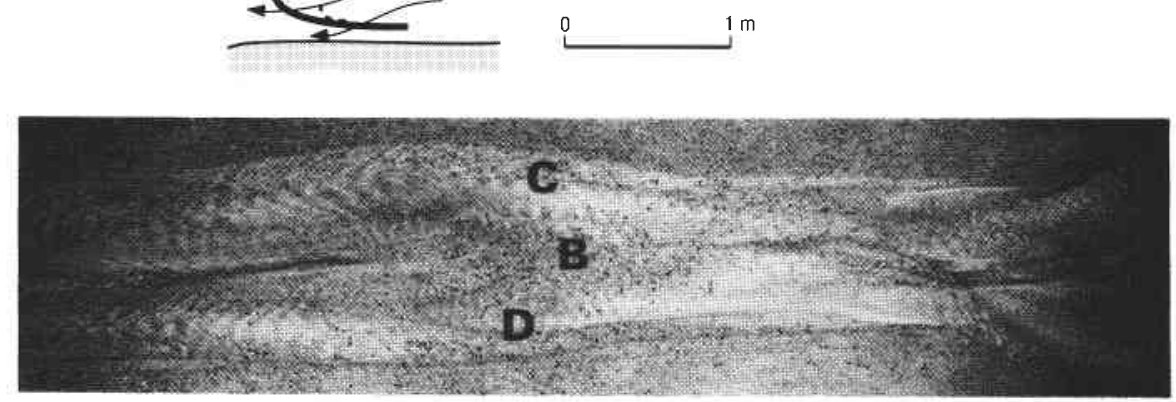

(c)

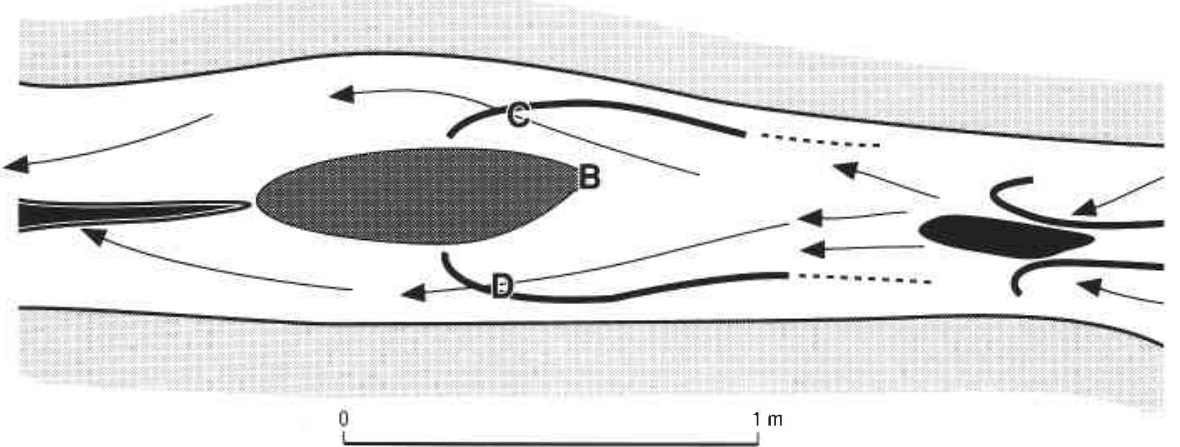

Fig. 6. Transverse bar conversion braiding mechanism. See text for description. The time elapsed between $(a)$ and $(c)$ is $10 \mathrm{~min}$. Flow is right to left. 


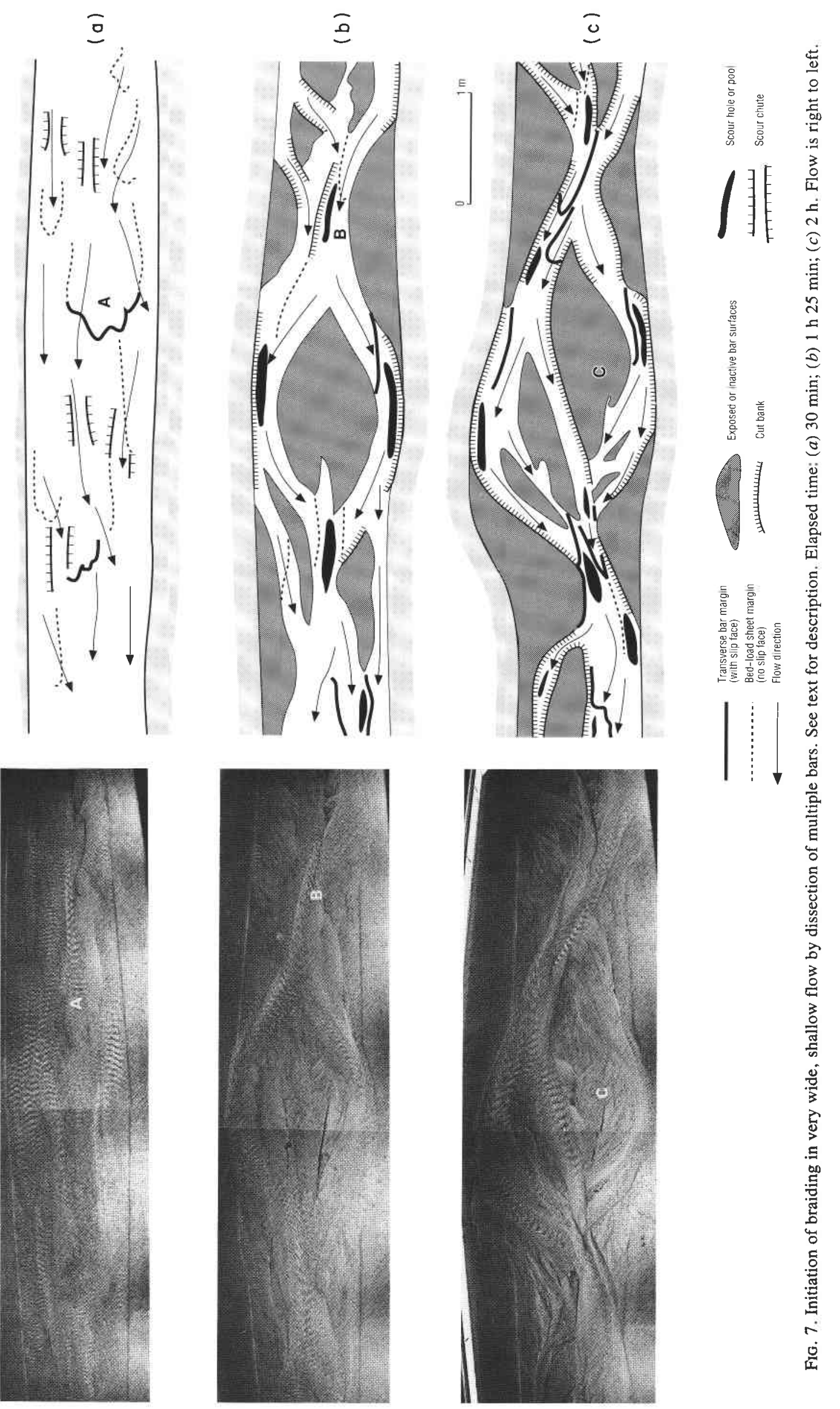


This is informal confirmation of Church and Jones' (1982) assumption about the lower limit of relative depth for bar formation. Below this limit braiding may be dominated by the stalling of bed-load sheets or perhaps by the chute and lobe features described by Southard et al. (1984), but not observed in the experiments reported here.

It is also possible to put forward a simple hydraulic argument to indicate the order of magnitude of local aggradation required to cause initial stalling of a gravel sheet in the channel (M. A. Church, personal communication, 1990), and hence the plausibility of suggesting its role in initiating braiding. Given bed shear stress close to critical in these very shallow channels, only slight shoaling and consequent local reduction in bed shear stress (assuming constant slope and approximately uniform flow) would be required to initiate deposition (the central bar case). At higher bed shear stress, the necessary local shoaling would be greater, but still small in absolute magnitude. Crudely, for $h / D_{50}$ of 9 and nondimensional bed shear stress of 0.09 , shoaling equivalent to only two or three times $D_{50}$ might be sufficient to bring the nondimensional bed shear stress down to 0.06 , and therefore close to critical entrainment conditions. This could be accomplished by two or three bed-load sheets overriding each other (the transverse bar conversion case). In the chute cutoff case channel widening, plus directing of sediment into shallower areas may also be necessary. Using this approximation based on known characteristics of the sediment and channel hydraulics, it appears that stalling of bed-load sheets is a reasonable mechanism for initiating braiding in gravel channels.

\section{Transverse bar conversion and chute cutoff}

Braiding by flow division atop large transverse unit bars ("transverse bar conversion") is seen frequently in braided streams, particularly downstream of confluences (Ashmore 1982). The potential importance of, or distinction from, falling-stage bar dissection in this process was discussed earlier. The general flow and sediment transport conditions (relative depth and sediment mobility) for the occurrence of symmetrical transverse unit bars, and hence for the occurrence of this braiding process, are similar to those for the formation of the asymmetrical unit bars (point dunes, alternating bars, or diagonal unit bars) that are a precursor of chute cutoff braiding.

The initial conditions at the beginning of run 2 in which transverse bar conversion braiding was observed are little different from several runs in which chute cutoff braiding prevailed. The only distinction between the conditions of transverse bar conversion rather than chute cutoff seems to be between upstream flow configurations that lead to symmetrical rather than asymmetrical bar development. The symmetrical arrangement might be favoured in wider initial channels where double-row bars instead of alternating bars might occur (see Bridge 1985, Fig.1).

Once braiding was established, both processes could be seen to be operating to maintain braiding in most runs. In some cases of braiding associated with asymmetrical bars, cutoff occurred at such an early stage in point bar development that there was almost no distinction from the bar conversion process. The bar conversion process and the cutoff process might be thought of as end members of a continuum of processes with a similar basic mechanism but different geometry (and, implicitly, greater channel sinuosity), ranging from symmetrical transverse bars to progressively asymmetrical bars and point bars.

\section{Transverse bar conversion and central bar braiding}

The transverse bar conversion also bears some morphological similarity to the central bar mechanism. Both involve vertical accretion of bed-load sheets, initiation of braiding by stalling of bed load in the centre of the channel and consequent flow splitting. The distinction between the two is the much higher sediment mobility in the bar conversion braiding, which leads to the development of the more pronounced bed forms and greater bed scour both upstream and downstream of the flow division. The increased bed-load capacity and greater bed scour encourage bar formation and thus propagate braiding downstream. At the same time, greater excess shear stress may encourage bank erosion and lateral growth of the braid bar. This increases the sinuosity of the channels, increases the confluence angle downstream of the braid bar, and thereby favours greater confluence scour (Ashmore and Parker 1983). The absence of pronounced bed scour, the low confluence angle, and the low bank erosion rates all characterize the central bar example (Fig. 5). It is noticeable that the cases of central bar braiding in these experiments were almost all solitary braids in an otherwise unbraided channel, and this process may be typical of streams barely above the threshold for braiding.

Thus, the difference in conditions leading to these two different morphologies is primarily sediment mobility, and hence its influence on bed-form regime and bed scour. This is also true of the distinction between chute cutoff and central bar braiding. Presumably, as the excess shear stress (excess stream power) increases, streams in which central bar braiding dominates are transformed to more active streams in which bed forms and confluence scour begin to favour the bar dissection or chute cutoff braiding processes. The more active streams are also likely to show higher braiding intensity and more rapid changes in channel configuration after the braided pattern is established.

\section{Multiple bar dissection}

The initiation of braiding from multiple bars appears to be a special case that applies only to channels with very high width/depth ratio. The geometric and hydraulic criteria for the occurrence of multiple bars and braiding have been investigated by Fujita (1989). The bars developed in run B appear to fit Fujita's (1989) mode 2 or 3 and plot within the braided regime on his Fig. 24. This channel geometry requirement for multiple bar braiding agrees in principle with the results of stability analyses. In the context of this paper, the physical sedimentary processes occurring in multiple bar braiding resemble the central bar or bar dissection braiding process (usually the former because of the limited flow depth for bar development). Local decline of competence in a flow expansion or over a bar top initiates dissection of the submerged multiple bars. The wide channel merely allows the lateral proliferation of these mechanisms, while flow depth and bed shear stress determine the bedform geometry (i.e., the distinction between bed-load sheets and transverse bars).

Once braiding was established in run B it was maintained by the cutoff, avulsion, and bar conversion mechanisms. None of the braided anabranches developed sufficiently large width/ depth ratios to allow multiple bar dissection to occur. The multiple bar dissection process is probably much more common in sand-bed than gravel-bed streams. However, Boothroyd and Nummedal (1978) illustrate multiple-row braid bars on large outwash fans that may be prototypes for the multiple bar braiding mechanism.

\section{Discussion}

In general, direct physical explanations of the sedimentary processes leading to braiding have relied on arguments related to rapid bank retreat yielding large quantities of bed-load- 
calibre sediment causing local thalweg shoaling (e.g., Carson $1984 a$ ), and spatial or temporal changes in bed-load competence and (or) capacity (e.g., Church and Gilbert 1975; Ferguson 1987; Fujita 1989). From the descriptions of braiding mechanisms in this paper it is possible to provide more details about the role of these factors, and to suggest that the role of each may vary with the prevalent braiding mechanism.

The crucial consideration for the understanding of chute cutoff braiding is to establish the hydraulic, morphological, and sedimentological circumstances under which the point bars of bed-load channels are susceptible to chute cutoff. A related problem is to explain why in some cases cutoff occurs at very low sinuosities, when only rudimentary point bars or simple asymmetrical (diagonal) unit bars are present, while in other cases considerable lateral accretion occurs before chute cutoff is initiated. In the low-sinuosity case the braiding process is merely a skewed form of the transverse bar conversion process. The more fully developed chute cutoff of an established point bar may involve some of the elements of the bar conversion process, especially local vertical accretion by bed-load sheets, but also involves a delay in the onset of braiding during which lateral accretion of a complex point bar occurs, thus giving rise to a distinctive morphology and braiding process.

The susceptibility to chute cutoff appears to be related to the inability of bed-load channels to build the inner point bar to bank-full elevation (or, alternatively, to fill the chute with fine sediment) in the absence of fine-grained suspended sediment deposition (Carson 1986), coincident with local shoaling on the bar head. The role of suspended sediment in stabilizing point bars (or "pseudomeanders") and preventing chute cutoff in laboratory streams has been demonstrated experimentally by Schumm and Khan (1972).

Because of the low elevation of the inner point bar surface bed-load channels are always vulnerable to flow over the point bar incising and enlarging the slough channel. At constant discharge in the laboratory this was most common at times when there was rapid erosion of the concave bank immediately upstream of the chute (i.e., rapid downstream translation of that portion of the bend) and the concurrent passage of a slug of sediment. Under these circumstances the flow was redirected over the point bar, perhaps aided by local channel aggradation during the passage of the bed-load slug leading to avulsion and chute cutoff. Thus, local bank erosion causing a change in the position and geometry of the concave bank immediately upstream of the point bar head, the supply bed-load pulses (sheets) and local aggradation, combined with the absence of fine-grained bar tail and bar top deposits, cause braiding by chute cutoff.

Vertical accretion of bed-load sheets, and a loss of competence near the centre of the channel are the dominant elements of the central bar and transverse bar conversion braiding processes. Subsequent changes in water surface elevation are probably also important to progression of the process. Declining competence during the development of the flow expansion plays a role in the apparent tendency for the bifurcation to originate with the deposition of coarse particles (Leopold and Wolman 1957). However, the accumulation of coarse particles may be associated with the stalling of bed-load sheets. In this case the coarse deposit may represent the downstream margin of a sheet resulting from the tendency for coarse particles to outrun finer ones within the same bed-load sheet (Meland and Norrman 1969), rather than being the result of selective deposition of the coarse fraction. Similarly, the coarser sediment at the head of the resulting braid bar might derive from the downstream fringe of a prograding gravel sheet

Once flow is diverted and concentrated around the bar margins, emergence of the braid bar follows as a result of incision of the marginal channels and addition of sediment to the head of the bar. The exact nature of the changes in the velocity and bed-load transport in the zone immediately downstream of a flow convergence, and atop slip-face bars, remains to be examined in detail to quantitatively document and model the process.

Braiding initiation from shallow sheet flow seems to require a basic mechanism no different than that for central bar or bar-top braiding. The formation of depositional sheets downstream of erosional chutes in the shallow sheet flow is essentially the same as the formation of bed-load sheets and bars downstream of flow expansions in a single deeper, narrower channel.

The chute cutoff process appears, in some cases, to be almost identical to the transverse bar conversion process. Braiding is initiated by vertical accretion on asymmetrical unit bars. In cases where the development of a sinuous channel with complex point bars precedes the onset of braiding, the process is more akin to avulsion and may be aided by bank erosion and channel migration, and by the favourable local slopes into the slough channel. Nevertheless, the flume observations suggest that the onset of braiding in this case, albeit in the context of a distinctive bed morphology, is triggered by the accretion of bed-load sheets in the flow expansion downstream of the bend apex that are instrumental in diverting part of the flow into the chute. Rather than being a distinctive fundamental braiding mechanism, this is a modification, due to alternating bar formation and channel sinuosity, of the bed-load sheet accretion and loss of competence in a flow expansion responsible for braiding in the other cases.

Thus, there appear to be several distinct braiding processes, which are ultimately the result of a single fundamental sedimentation mechanism. The central bar, transverse bar conversion braiding (not falling-stage dissection), and multiple bar braiding processes, although they are associated with different bed-form morphologies and sediment mobility conditions, are all primarily a response to the rapidly changing flow and sediment transport field in a developing flow expansion. The onset of braiding is the direct result of the stalling and vertical accretion of bed-load sheets in the flow expansion. The chute cutoff mechanism, although aided by other factors, and associated with existing complex point bars, rather than simple unit bars, also appears to be triggered by accretion of bed-load sheets (thalweg shoaling) in the flow expansion downstream of the bend apex. Supply of bed-load-calibre sediments from the banks immediately upstream (Carson 1984a) plays a more important role in this braiding process than in any of the others.

Flow instability leading to regularly spaced bar forms and thalweg sinuosity is implicated in the chute cutoff, bar dissection, and multiple bar processes. This emphasizes the connection between the sedimentary processes described herein and the mathematical stability analyses of channel pattern described in the introduction. In the case of the central bar mechanism the instability appears to be damped and isolated braids occur. In the other cases, where sediment mobility is greater, the bed scour by secondary currents around, and downstream of, the initial braid are vital to propagating the braiding process downstream. 
Once braiding is established, all of these processes may recur to promote further braiding within any one stream. The general conditions of sediment mobility and instability in the stream will determine which is prevalent but in many cases more than one of these processes is responsible for the maintenance of the braided pattern. This combination of bed-form instability and local changes in competence promoting braiding has been suggested previously by Cheetham (1979), on the basis of morphological changes in a braided river during a flood event.

In all cases, while local bed-load transport capacity, bed-load supply, bank erosion, and aggradation are important to the braiding process, the sedimentary processes leading to braiding are also closely tied to the presence and stability of the bed forms. Thus, the bed-form "regime" determines the type of bed forms present and therefore the prevalent braiding process.

Once braiding was established in the laboratory channels increased braiding activity was often associated with the downstream passage of "waves" of bed load. These waves caused local aggradation, which often took the form of sedimentation from migratory unit bars and, in detail, the increased braiding was associated with the incision and cutoff of bars newly formed thereby, plus avulsion into abandoned channels (Ashmore 1987). Thus, short-term, reach-by-reach, transience in bed-load supply and local aggradation and bar formation associated with increased supply are important to the initiation and maintenance of braiding regardless of the exact process at work. This transience can maintain braiding without the necessity for overall aggradation in the braided river, and in conditions of steady flow and steady mean sediment supply and transport rate.

Braiding in gravel-bed streams may originate from an initially straight, undivided channel by one of a number of mechanisms, depending on the sediment and flow characterisItics. The classic central bar mechanism described by Leopold and Wolman (1957) is one of these, but not necessarily the prevalent one. The experiments described here show that at constant discharge, and for a given particle-size distribution, other braiding mechanisms are common. These are chute cutoff of solitary point bars or alternating bars, flow division around the downstream end of symmetrical transverse unit bars ("transverse bar conversion"), and dissection of multiple bars. The hydraulic conditions, particularly the sediment mobility and bed-form regime, are important controls on the sedimentary processes leading to braiding.

The Leopold and Wolman (1957) central bar mechanism occurs in channels in which the bed shear stress is only slightly above critical. In these channels the downstream ends of stalled, faint gravel sheets form the nucleus of the braid bar.

At higher bed shear stress in relatively narrow channels the bed begins to deform into more obvious, alternating bars, which eventually leads to braiding by chute cutoff. The occurrence of a cutoff often coincides with the arrival of a pulse of bed load that may temporarily raise the bed and water surface to allow overtopping of the point bar. The greater shear stress may also contribute to rapid bank erosion and the inability of the stream to establish a stable single channel. The absence of fine-grained suspended sediment deposits to contribute to vertical accretion of point bars is also a factor in the susceptibility to chute cutoff.

Flow division atop isolated slip-face, transverse bars ("transverse bar conversion"), formed in channels with high sediment mobility, is also a common bifurcation mechanism often associated with flow expansion downstream of symmetrical anabranch confluences. This morphology is similar in many respects to that of the central bar mechanism. The distinction between the two rests on the greater sediment mobility in the bar dissection process, which gives rise to more pronounced bed forms and greater bed scour in the confluences between successive braid bars, which encourages propagation of the braiding process. Asymmetrical unit bars often show bar conversion braiding that is morphologically akin to the chute cutoff process.

In very wide channels dissection of multiple bars occurs; however, this particular process is likely to be rare in gravel-bed braided streams because of the necessity for very high width/ depth ratios.

Instability of flow and bed-load transport appears to be at the root of all of these mechanisms, except central bar braiding, which is often an isolated occurrence of purely depositional origin. This contrasts with the other processes, all of which involve an element of reworking of the initial deposits by secondary flows that are sufficiently competent to propagate braiding downstream as well as to modify the form of the initial deposit. Thus, the latter are much more dynamic processes associated with greater bed sediment mobility (i.e., bed shear stress). The distinction in conditions of occurrence of the three mechanisms other than central bar braiding appears to rest largely on differences in channel geometry (e.g., narrow versus wide channels for chute cutoff and multiple bar braidng respectively) and flow and bed-form symmetry (e.g., symmetrical transverse bars versus asymmetrical bars in the bar conversion and chute cutoff processes respectively).

The underlying "cause" (i.e., fundamental sedimentary mechansim) of braiding in these experiments using a single particle-size distribution and constant discharge appears to be essentially the same for all the processes described. In the cases of central bar braiding, transverse bar conversion braiding, and multiple bar braiding, the vertical accretion of bed-load sheets and the loss of competence in the centre of the channel occurring during the development of a lateral flow expansion are the key to explaining when braiding occurs. In the case of chute cutoff braiding, the occurrence of braiding rests on the susceptibility of point bars in low-sinuosity bed-load channels to overtopping and dissection. This overtopping seems to be triggered by the advection of bed-load sheets into the flow expansion downstream of the bend apex (i.e., the head of the point bar). This suggests that local flow expansion, thalweg shoaling, and stalling of bed-load sheets is instrumental in causing chute cutoff braiding, as it is in the other braiding processes, albeit in a morphologically different setting from the other processes. Rapid bank retreat immediately upstream is also an important factor in this case.

Although these processes are described from simple, initially straight channels with flat beds, the chute cutoff, central bar, and transverse bar conversion braiding processes are all observed to occur within existing braided channels and are therefore important to the maintenance of braiding once it is established. In most cases braiding in any particular river will be maintained by a combination of these processes, depending upon local flow and sediment transport conditions at points where braiding occurs, as well as the general flow and sediment mobility (excess stream power) conditions in the stream. Short-term transience of bed-load transport in braided channels, 
even at constant discharge and constant mean bed-load supply and transport rate, is important to all of these braiding processes and to the maintenance of braiding.

\section{Acknowledgments}

These experiments form part of a Ph.D. thesis supervised by Dr. John Shaw in the Department of Geography, University of Alberta, and funded by a Killam predoctoral scholarship. The experiments were carried out in the Graduate Hydraulics Laboratory, Department of Civil Engineering, with the technical assistance of Sheldon Lovell and funding from Natural Sciences and Engineering Research Council of Canada grants to Dr. Shaw and Dr. Gary Parker. I am grateful for reviews by John Shaw, Norman Smith, and especially, Michael Church, which have contributed to considerable improvements in the paper. Michael Church finally convinced me to (almost) agree with him on the question of fundamental braiding mechanisms. The diagrams were drafted by Gordon Shields; those accompanying photographs are based on sketches by Dave Huntley. Ian Craig worked conscientiously to successfully overcome the problems of printing the photographs.

Allen, J. R. L. 1982. Sedimentary structures: their character and physical basis, volume 1. Developments in Sedimentology, 30A, Elsevier, Amsterdam.

Ashley, G. M. 1990. Classification of large-scale subaqeous bedforms: a new look at an old problem. Journal of Sedimentary Petrology, 60: 160-172.

AsHMORE, P. E. 1982. Laboratory modelling of gravel braided stream morphology. Earth Surface Processes and Landforms, 7: 201-225.

1987. Bed load transfer and channel morphology in braided streams. In Erosion and Sedimentation in the Pacific Rim. Edited by R. L. Beschta, T. Blinn, G. E. Grant, G. G. Ice, and F. J. Swanson. International Association of Hydrological Sciences, Publication 165, pp. 333-341.

1988. Bed load transport in braided gravel-bed stream models. Earth Surface Processes and Landforms, 13: 677-695.

Ashmore, P. E., and Parker, G. 1983. Confluence scour in coarse braided streams. Water Resources Research, 19: 392-402.

Bluck, B. J. 1976. Sedimentation in some Scottish rivers of low sinuosity. Transactions of the Royal Society of Edinburgh, 69: 425-456.

1979. Structure of coarse grained braided alluvium. Transactions of the Royal Society of Edinburgh, 70: 181-221.

Boothroyd, J. C., and Nummedal, D. 1978. Proglacial braided outwash: a model for humid alluvial fan deposits. In Fluvial sedimentology. Edited by A. D. Miall. Canadian Society of Petroleum Geologists, Memoir 5, pp. 641-668.

BRIDGE, J. S. 1985. Paleochannel patterns inferred from alluvial deposits: a critical evaluation. Journal of Sedimentary Petrology, 55: 579-589.

CARSON, M. A. 1984a. The meandering-braiding threshold: a reappraisal. Journal of Hydrology (Amsterdam), 73: 315-334.

- 1984b. Observations on the meandering-braided river transition, the Canterbury Plains, New Zealand: part one. New Zealand Geographer, 40: 12-17.

$1984 c$. Observations on the meandering-braided river transition, the Canterbury Plains, New Zealand: part two. New Zealand Geographer, 40: 89-99.

1986. Characteristics of high-energy "meandering" rivers: the Canterbury Plains, New Zealand. Geological Society of America Bulletin, 97: 886-895.

Cheetham, G. H. 1979. Flow competence in relation to stream channel form and braiding. Geological Society of America Bulletin, 90: $877-886$.

СHurch, M. 1970. Baffin Island sandar: a study of arctic fluvial environments. Ph.D. thesis, University of British Columbia, Vancouver.

1972. Baffin Island sandurs: a study of arctic fluvial processes. Geological Survey of Canada, Bulletin 216.

Church, M., and Gilbert, R. 1975. Proglacial fluvial and lacustrine environments. In Glaciofluvial and glaciolacustrine sedimentation. Edited by A. V. Jopling and B. C. McDonald. Society of Economic Palacontologists and Mineralogists, Special Publication 23, pp. 22 100.

Church, M., and Jones, D. 1982. Channel bars in gravel-bed rivers. In Gravel-bed rivers. Edited by R. D. Hey, J. C. Bathurst, and C. R. Thorne. John Wiley \& Sons, Chichester, pp. 291-324.

DAviEs, T. R., and LeE, A. I. 1988. Physical hydraulic modelling of width reduction and bed level changes in braided rivers. Journal of Hydrology (N.Z.), 27: 113-127.

Davoren, A., and Mosley, M. P. 1986. Observations of bed load movement, bar development and sediment supply in the braided Ohau River. Earth Surface Processes and Landforms, 11: 643-652.

ENGELUNd, F., and SkovgaARD, O. 1973. On the origin of meandering and braiding in alluvial streams. Journal of Fluid Mechanics, 57: 289-302.

FERGUSON, R. 1987. Hydraulic and sedimentary controls of channel pattern. In River channels: environment and process. Edited by K. S. Richards. Institute of British Geographers, Special Publication 17, pp. 181-193.

FERGUSON, R. I., and Werrity, A. 1983. Bar development and channel changes in the gravelly River Feshie, Scotland. In Modern and ancient fluvial systems. Edited by J. D. Collinson and J. Lewin. International Association of Sedimentologists, Special Publication 6, pp. $181-193$.

FREDSOE, J. 1978. Meandering and braiding of rivers. Journal of Fluid Mechanics, 84: 609-624.

FriedKIN, J. F. 1945. A laboratory study of the meandering of alluvial rivers. United States Waterways Experimental Station, Vicksburg, MS.

FuJITA, Y. 1989. Bar and channel formation in braided streams. In River meandering. Edited by S. Ikeda and G. Parker. American Geophysical Union, Water Resources Monograph 12, pp. 417-462.

Fujita, Y., and Muramoto, Y. 1988. Multiple bars and stream braiding. In International conference on river regime. Edited by W. R. White. Hydraulics Research Limited, Wallingford, United Kingdom, pp. 289-300.

Hein, F. J., and Walker, R. G. 1977. Bar evolution and development of stratification in the gravelly, braided Kicking Horse River, British Columbia. Canadian Journal of Earth Sciences, 14: 562570.

HickIN, E. J. 1969. A newly-identified process of point bar formation in natural streams. American Journal of Science, 267: 999-1010.

HoNG, L. B., and Davies, T. R. H. 1979. A study of stream braiding. Geological Society of America Bulletin, 79: 391-394.

IKEDA, H. 1973. A study of the formation of sand bars in a experiniental flume. Geographical Review of Japan, 46(7): 435452.

1984. Prediction of alternate bar wavelength and height. ASCE Journal of Hydraulic Engineering, 110: 371-386.

JAEGGI, M. N. R. 1984. Formation and effects of alternate bars. ASCE Journal of Hydraulic Engineering, 110: 142-156.

Kinoshita, R. 1957. Formation of dunes on river beds-an observation on the condition of river meandering. Proceedings of the Japan Society of Civil Engineers, 42: 1-21.

Knighton, D. 1984. Fluvial forms and processes. Edward Arnold, London.

KRIGSTRÖM, A. 1962. Geomorphological studies of sandur plains and their braided rivers in Iceland. Geografiska Annaler, 44: 328-346.

LEOPOLD, L. B., and WolmaN, M. G. 1957. River channel patterns, braided meandering and straight. United States Geological Survey, Professional Paper, 262B.

LEWIN, J. 1976. Initiation of bed forms and meanders in coarse- 
grained sediment. Geological Society of America Bulletin, 87: 281-285.

Meland, N., and Norrman, J. O. 1969. Transport velocities of individual size fractions in heterogeneous bedload. Geografiska Annaler, 51A: 127-144.

MoRISAWA, M. 1985. Rivers: form and process. Longman, London. PARKER, G. 1976. On the cause and characteristic scales of meandering and braiding in rivers. Journal of Fluid Mechanics, 76: 457-480.

1979. Hydraulic geometry of active gravel rivers. Journal of the Hydraulics Division, 105: 1185-1201.

RICHARDS, K. 1982. Rivers: form and process in alluvial channels. Methuen, London.

$\stackrel{m}{\rightleftharpoons}$ RuNDLE, A. S. 1985a. The mechanism of braiding. Zeitschrift für Geomorphologie, Supplement Band, 55: 1-13.

- 1985 b. Braid morphology and the formation of multiple channels, the Rakaia, New Zealand. Zeitschrift für Geomorphologie, Supplement Band, 55: 15-37.

Schumm, S. A., and Khan, H. R. 1972. Experimental study of channel patterns. Geological Society of America Bulletin, 83: 1775-1770.

Schumm, S. A., Mosley, M. P., and Weaver, W. E. 1987. Experimental fluvial geomorphology. John Wiley and Sons, New York.
Smith, N. D. 1974. Sedimentology and bar formation in the upper Kicking Horse River, a braided meltwater stream. Journal of Geology, 82: 205-224.

1985. Proglacial fluvial environment. In Glacial sedimentary environments. Edited by G. M. Ashley and J. Shaw. Society of Economic Paleontologists and Mineralogists, Short Course No. 16, pp. $85-134$.

Southard, J. B., Smith, N. D., and Kuhnle, R. A. 1984. Chutes and lobes: newly identified elements of braiding in shallow gravelly streams. In Sedimentology of gravels and conglomerates. Edited by E. H. Koster and R. J. Steel. Canadian Society of Petroleum Geologists, Memoir 10, pp. 51-59.

Whiting, P. J., Dietrich, W. E., Leopold, L. B., Drake, T. G., and Shreve, R. L. 1988. Bedload sheets in heterogeneous sediment. Geology, 16: 105-108.

Wolman, M. G., and BRUSH, L. M. 1961. Factors controlling the size and shape of stream channels in coarse, non-cohesive sand. United States Geological Survey, Professional Paper 282-G.

YALIN, M. S. 1971. Theory of hydraulic models. Macmillan, London. 1977. Mechanics of sediment transport. 2nd ed. Pergamon Press, Oxford. 